\title{
Self-driven cracking by crack face cooling during thermal shock testing of ceramics
}

\author{
Jianye Wang and Luc J. Vandeperre \\ Department of Materials and Centre for Advanced Structural Ceramics, Imperial College \\ London, London SW7 2AZ, UK
}

Submitted to the Journal of the American Ceramic Society 


\title{
Self-driven cracking by crack face cooling during thermal shock testing of ceramics
}

\author{
Jianye Wang and Luc J. Vandeperre \\ Department of Materials and Centre for Advanced Ceramics, Imperial College London, \\ London SW7 2AZ, UK
}

Keywords: thermal shock; ceramics; fracture

\begin{abstract}
Good predictions of the extent of crack growth during thermal shock can normally be obtained by calculating the crack driving force for a single crack while assuming that the cracking has no effect on the temperature distribution in the body. However, experiments have shown that sometimes cracks grow much deeper than predicted. To ascertain whether this might be due to cooling by water penetration into the cracks, the effect of cooling along the crack faces on the crack driving force is calculated and predictions for the extent of cracking are compared with experiments on soda-lime glass. It is confirmed that cooling along the crack faces causes self-driven crack propagation. The effect of cooling in the cracks is only important when the fracture energy is low compared with the severity of the thermal shock, consistent with the observation that excessive cracking tends to be observed only in materials with low fracture energies.
\end{abstract}

\section{Introduction}

The thermal shock resistance of ceramics is typically measured by quenching small test bars into water, see e.g. [1-6]. This test is based on Hasselman's[7] pioneering work in understanding thermal shock. He carried out a simplified analysis in which a bar was assumed to be constrained and cooled uniformly through a temperature difference. He predicted crack lengths as a function of the severity of quench by considering the balance 
between the energy released upon cracking and the surface energy created. He found that small defects extend in an unstable burst during which more energy is released than needed to grow the crack, whereas long cracks only extend in a stable manner. More detailed analyses[8-11] in which the temperature and stress distribution during thermal shock is formally taken into account, have confirmed the predictions of this simple model. Davidge and Tappin[12] introduced another test, later modified by Bahr[13]. The test differs from normal quench tests in that the large faces of plate shaped samples are covered with thermal insulation. Upon quenching through-thickness cracks grow inwards from the cold edges and the depth to which they penetrate the sample can be seen after removing the insulation. This test has helped to explain why spalling is more likely at temperature differences only mildly in excess of the critical one for cracking[13] and why a pattern of long and short cracks forms $[9$, 14]. These experiments, however, have not confirmed Hasselman's suggestion that cracks would grow beyond the prediction based on the instantaneous release of energy by recuperating excess energy released during unstable growth at temperatures slightly above the critical temperature at which cracking starts. This mechanism was invoked to explain a plateau in the strength versus quench temperature difference, $\Delta \mathrm{T}$, that is sometimes observed, see e.g.[15]. Rather, it has been observed that in many cases both the onset of cracking and the crack lengths after thermal shock are predicted rather well if it is assumed that only the instantaneous release of strain energy drives cracking[10, 11, 16]. However, in ceramics with low fracture energies the crack lengths exceed the predicted lengths for large values of the quench temperature difference, $\Delta T[16]$. It was suggested that a possible reason for this could be the additional cooling caused by water being sucked into the cracks. Evidence that this does occur was obtained by quenching an alumina plate by bringing it in contact with water containing black ink. After failure the cracks in the alumina were found to have been stained by the ink proving that water is indeed sucked into the cracks.

This paper reports experiments and calculations carried out to clarify the influence of cooling of the crack faces on the crack driving force during thermal shock. 


\section{Experimental methods and calculation methodology}

\section{Thermal shock testing}

Thermal shock testing was carried out on soda-lime glass microscopy slides (Fisherbrand, Fisher Scientific, UK) measuring $75 \mathrm{~mm} \times 25 \mathrm{~mm} \times 1 \mathrm{~mm}$. The glass slides were heated in a muffle furnace to a desired temperature and quenched by bringing one edge in contact with water at room temperature. Crack spalling during quenching from low temperatures was avoided by introducing a sufficient number $\left(0.2-0.5 \mathrm{~mm}^{-1}\right)$ of scratches to act as starting defects for the cracks.

\section{Thermomechanical property measurements and predictions of thermal shock damage}

The density was determined by measuring the mass and the dimensions of the slides. The elastic modulus of the glass, E, was determined by impulse excitation (Grindosonic Mk5, Lemmens, Belgium). The technique consists of exciting the resonant bending vibration in the sample and measuring its frequency, $f$. For a rectangular plate, the relation between the resonant frequency and the elastic modulus is given by[17]:

$$
E=0.9465\left(\frac{m \cdot f^{2}}{b}\right)\left(\frac{L}{t}\right)^{3} \cdot T_{1}
$$

where $L$ is the length of the plate, $t$ its thickness, $b$ its width, $m$ its mass and $T_{1}$ a correction factor, which depends on the dimensions and the Poisson's ratio of the material and can be calculated with an expression given in [17]. The Poisson's ratio was assumed to amount to 0.2. The toughness of the glass was determined by measuring the crack lengths emanating from a Vickers indentation. Indents were made at two loads (9.8 and $29.5 \mathrm{~N})$ and the toughness calculated using[18]:

$$
K_{I C}=0.016 \sqrt{\frac{E}{H}} \frac{F}{c^{3 / 2}}
$$


where $H$ is the hardness, $F$ the applied load and $c$ the length of the crack measured from the centre of the indent. The measured values of fracture toughness and Young modulus where then used to calculate the critical strain energy release rate or fracture energy, $R$, using[19]:

$$
R=\frac{\left(1-v^{2}\right) K_{I C}^{2}}{E}
$$

The coefficient of thermal expansion of the glass was determined by dilatometry (Netzsch, DIL 402) in air between room temperature and $600^{\circ} \mathrm{C}$ with a heating rate of $10^{\circ} \mathrm{C}$ per minute. The heat capacity and thermal conductivity were taken from the literature[20, 21]. An overview of all properties used to predict the thermal shock response is given in Table 1.

To calculate the crack driving force, an established method[9-11, 14] was used in which first the evolution of the temperature distribution with time was calculated with a finite difference approach using commercial finite element software (ABAQUS 6.0, Simulia, USA). Only half the sample was modelled due to the symmetry, and crack driving forces were calculated for a single crack in the centre of the sample. This has been shown to give reasonable predictions of the longest cracks because the crack density decreases as cracks penetrate deeper. Cooling of the sample was modelled by applying a film condition to the edge of the sample in contact with water. The interfacial heat exchange coefficient, $h$, was set to $20 \mathrm{~W} \mathrm{~K}^{-1} \mathrm{~m}^{-2}$. The latter value was taken from measurements made for alumina in thermal shock[22]. The finite element software was also used to calculate the stress distribution in the sample assuming linear elastic behaviour. All calculations were made on an intact body. The transient temperature and stress distributions were calculated incrementally in small time steps $(0.1 \mathrm{~s})$, typically for times up to $20 \mathrm{~s}$ as it was found that for longer times the crack driving forces decay. The mesh size and the time step were the largest values which still gave accurate results as found by sensitivity studies.

The crack driving force was calculated separately from the stress distribution along the centre line using a weight function developed by Fett and Munz[23]. The advantage of this approach is that it allows estimating the stress intensity for a crack of any length from the stress distribution in a crack-free body by integration of the product of the stress, $\sigma$, with the weight function, $h$ : 


$$
K_{I}=\int_{0}^{a} h \sigma d x
$$

where

$$
h=\sqrt{\frac{2}{\pi a}} \frac{\left.\left(1-\frac{a}{t}\right)^{3 / 2}+\sum A_{\mu \nu}\left(1-\frac{x}{a}\right)^{v+1}\left(\frac{a}{t}\right)^{\mu}\right)}{\sqrt{1-\frac{x}{a}} \sqrt{\left(1-\frac{a}{t}\right)^{3}}}
$$

and $a$ is the crack length, $t$ the sample height, and $A_{\mu \nu}$ coefficients given in reference[23].

To simulate crack face cooling, a film condition was additionally applied along the central plane from the surface up to the predicted length of the crack. Only the heat exchange conditions were changed, no changes in mechanical boundary conditions were made. Hence, any reported stress distributions are the stress distributions in an uncracked body. The length of the crack at any moment in time was determined in a step-wise manner. In the first simulation step, when the damage is limited to the scratches, which were made on the glass edge in the experiments to ensure a sufficient number of cracks initiates, no cooling from crack faces was assumed to occur and the crack driving force was calculated accordingly. The results were reviewed, and at the moment in time where the crack driving force rose above the fracture energy for the starter defects, a crack was assumed to propagate from the starter defects and allowed to extend to the predicted stable length, i.e. the length at which the crack driving force drops below the fracture energy again. It would perhaps have been more accurate to include crack face cooling on the starter defects, but since in all cases cracking was found to start in the first calculation step, this simplification will not affect the total propagation lengths, In the next calculation, a film condition was then applied up to the length reached by the crack at that moment in time and the calculation continued. The results were again reviewed, the progression of the crack determined and the film condition extended accordingly at the appropriate moment in time. This process was repeated until no further crack extension was predicted to occur for a given crack length or until failure of the sample. 


\section{Results and discussion}

Figure 1 shows a typical crack pattern obtained during the tests. A large number of cracks has initiated from the scratches made in the surface of the glass in contact with the water. and The presence of a sufficient number of cracks suppresses spalling and so that instead an hierarchical pattern of short and long cracks forms as the result of cracks competing for the crack driving force, which decays deeper into the sample as discussed in [9]

Figure 2 shows the experimentally obtained measurements of the length of the longest cracks versus quench temperature difference together with the standard prediction, which assumes that there is no cooling through the crack faces. In agreement with findings elsewhere for low fracture energy materials[24], as the quench temperature difference is increased, the experimental values exceed the standard prediction increasingly.

Also shown in Figure 2 is that if it is assumed that cooling through the crack faces is as efficient as cooling through the front face of the sample, i.e. an interfacial heat exchange coefficient, $h$, of $20 \mathrm{~kW} \mathrm{~K}^{-1} \mathrm{~m}^{-2}$, then the cracks are predicted to grow much deeper and in fact the predictions now overshoot the experimental values.

A sensitivity study was carried out to determine how strongly the crack depth at a fixed $\Delta T$ varies with assumed value of $h$. As shown in Figure 3, the predicted length of the crack increases linearly with the assumed value of the interfacial heat exchange coefficient within the crack. Clearly, the experimental results can be reproduced provided a value of about $1 \mathrm{~kW} \mathrm{~K}^{-1} \mathrm{~m}^{-2}$ is used. Therefore, this value was also used to predict the variation of crack length with $\Delta T$ and as shown in Figure 2 this single value is capable of predicting the crack lengths over the entire $\Delta \mathrm{T}$ range rather well. Hence, the excess cracking observed in glass here can be explained by assuming that water being sucked into the cracks can cause cooling with an efficiency of about $5 \%$ of the efficiency of the cooling through the front face of the sample. 
Obviously, a more detailed description, which takes into account the fluid flow and evaporation of water from the cracks, would enable this to be modelled more accurately, but this simple approach does allow discussing why the damage penetrates so deep for such low values of $\Delta \mathrm{T}$. Figure $4 \mathrm{a}$ illustrates that cooling through the crack tip leads to a cold front penetrating the sample much deeper than the main front. Figure $4 \mathrm{~b}$ illustrates how this influences the stress distribution. It is clear that the cooling at the tip of the crack causes a region with a small tensile stress to develop near the tip of the cool region. If these tensile stresses are high enough to keep driving the crack then the crack can become self-driven. That this occurs, can be seen quite clearly in Figure 5. In the presence of crack face cooling, the crack grows faster and has no difficulty growing deep into the material ahead of the thermal field as represented by predicted crack growth in absence of crack face cooling.

The final question that remains to be answered is therefore why cooling from within the cracks only influences the results of thermal shock tests of materials with low fracture energy. To clarify this, predictions were made for the distance a crack would penetrate the sample if the fracture energy of the glass would have amounted to 100 or $500 \mathrm{~J} \mathrm{~m}^{-2}$ instead of $10 \mathrm{~J} \mathrm{~m}^{-2}$. As can be seen in Figure 5, when the fracture energy is $500 \mathrm{~J} \mathrm{~m}^{-2}$, crack face cooling only causes a small increase in crack length ahead of a crack driven by the main thermal field alone. Hence, the cooling in the crack can not generate a strong enough crack driving force to overcome the much higher resistance to cracking in this material. Progression of the crack therefore remains bound by the progression of the main cooling front.

Figure 6 compares the maximum values for the crack driving force for any length of crack obtained without crack face cooling (dashed line) with the maximum values for the crack driving force for any length of crack for the three assumed fracture energies. A discussed above, when $R$ is low $\left(10 \mathrm{~J} \mathrm{~m}^{-2}\right.$ ), the crack can drive itself deeper, but the extent to which this is possible becomes much smaller when the fracture energy increases: for $100 \mathrm{~J} \mathrm{~m}^{-2}$ the predicted crack length increases from 9 to $14 \mathrm{~mm}$, and for $500 \mathrm{~J} \mathrm{~m}^{-2}$ the predicted crack length increases only from 5 to $7 \mathrm{~mm}$. This confirms that excess cracking due to crack face cooling will affect low fracture energy materials much stronger than high fracture energy materials, in agreement with observations. 


\section{Conclusions}

Thermal shock experiments on glass slides confirm that in low fracture energy materials cracks grow deeper than predicted from the main heat flow in the sample. However, the experimental results can be explained when cooling by water penetration into the cracks is accounted for. By fitting to the experimental observations, it is estimated that the latter cooling has a much reduced efficiency at about $5 \%$ of the cooling through the outer face of the sample. Further calculations have shown that in low fracture energy materials, this cooling is sufficient to drive the cracks independent of the main thermal field, but for tougher materials, the cracks can not grow without the main thermal field penetrating as well. This explains why discrepancies between predictions and observations in the literature have been limited to low fracture energy materials.

\section{References}

1. Yang, Z., et al., Thermal shock resistance of in situ formed SiC-BN composites. Materials chemistry and physics, 2008. 107: p. 476-479.

2. Salekeen, S., et al., Mechanical property degradation of a Nicalon fiber reinforced SiNC ceramic matrix composite under thermal shock loading. Composite structures, 2007. 78(4): p. 477-485.

3. Koh, Y.-H., et al., Thermal shock resistance of fibrous monolithic $\mathrm{Si}_{3} \mathrm{~N}_{4} / \mathrm{BN}$ ceramics. Journal of The European Ceramic Society, 2004. 24: p. 2339-47.

4. Boccaccini, D.N., et al., Thermal shock behaviour of mullite-cordierite refractory materials. advances in Applied Ceramics, 2007. 106(3): p. 142-148.

5. Monteverde, F., Resistance to thermal shock and to oxidation of metal diborides-SiC ceramics for aerospace application. Journal of the American Ceramic Society, 2007. 90(4): p. 1130-1138.

6. ASTM, Standard test method for determination of thermal shock resistance for advanced ceramics by water quenching, in ASTM. 2009, American Society for Testing and Materials: West Conshohocken, PA.

7. Hasselman, D.P.H., Strength Behavior of Polycrystalline Alumina subjected to thermal shock. Journal of the American Ceramic Society, 1970. 53(9): p. 490-95.

8. Bahr, H.A., et al., Multiple Crack Propagation in a strip caused by thermal shock. Theoretical and Appl. Fract. Mechanics, 1988. 10: p. 219-26.

9. Evans, A.G. and E.A. Charles, Structural Integrity in Severe Thermal Environments. Journal of the American Ceramic Society, 1977. 60(1-2): p. 22-28.

10. Vandeperre, L.J., et al., Thermal Shock of Layered Ceramic Structures with CrackDeflecting Interfaces. Journal of the American Ceramic Society, 2001. 84(1): p. 104110.

11. Vandeperre, L.J., Y. Inagaki, and W.J. Clegg, Thermal shock of porous silicon nitride with preferentially aligned grains. J. Mat. Res., 2003. 18(11): p. 2724-2729.

12. Davidge, R.W. and G. Tappin, Thermal Shock and Fracture of Ceramics. Transactions of the British Ceramic Society, 1967. 66: p. 405-22.

13. Bahr, H.A., G. Fischer, and H.J. Weiss, Thermal-Shock Crack Patterns Explained by Single and Multiple Crack Propagation. J. Mat. Sci., 1986. 21: p. 2716-2720. 
14. Bahr, H.A., U. Bahr, and A. Petzold, 1-d deterministic crack pattern formation as a growth process with restrictions. Europhysiscs letters, 1992. 19(6): p. 485-90.

15. Lutz, E.H., M.V. Swain, and N. Claussen, Thermal Shock Behavior of Duplex Ceramics. Journal of the American Ceramic Society, 1991. 74(1): p. 19-24.

16. Chen, Y., L.J. Vandeperre, and W.J. Clegg, The effect of porosity in thermal shock. Journal of Materials Science. 43(12): p. 4099-4106.

17. ASTM C1259-01 Standard Test Method for Dynamic Young's Modulus, Shear Modulus, and Poisson's Ratio for Advanced Ceramics by Impulse Excitation of Vibration. 2001, ASTM.

18. Gong, J., Y. Chen, and C. Li, Statistical analysis of fracture toughness of soda-lime glass determined by indentation. Journal of Non-Crystalline Solids, 2001. 279: p. 219223.

19. Lawn, B.R. and T.R. Wilshaw, Fracture of Brittle Solids. Cambridge Solid State Science Series, ed. R.W. Cahn, A.J. Forty, and I.M. Ward. 1975, Cambridge: Cambridge University Press. 204.

20. Lide, D.R., ed. CRC Handbook of Physics and Chemistry. 81st ed. 2001, CRC Press: London.

21. Touloukian, Y.S., ed. Thermophysical Properties of High Temperature Solid Materials. Vol. 4, part II. 1967, McMillan: New-York. p1793.

22. Lee, W.J., Y. Kim, and E.D. Case, The effect of quenching media on the heat transfer coefficient of polycrystalline alumina. Journal of Materials Science, 1993. 28: p. 207983.

23. Fett, T. and D. Munz, Determination of Fracture Toughness at High Temperature after Subcritical Extension. Journal of the American Ceramic Society, 1992. 75(11): p. 3133-36.

24. Yuan, C., The effect of porosity in thermal shock. Journal of materials science, 2008. 43(12): p. 4099-4106. 
Table 1. Materials properties of soda-lime glass used for simulation

\begin{tabular}{ll}
\hline Property & Value \\
\hline Density & $2530 \mathrm{~kg} \mathrm{~m}^{-3}$ \\
Young modulus, $\mathrm{E}$ & $72 \mathrm{GPa}$ \\
Poisson's ratio, $v$ & 0.2 \\
Coefficient of thermal expansion, $\alpha$ & $10 \times 10^{-6} \mathrm{~K}^{-1}$ \\
Heat capacity, $C_{\mathrm{p}}$ & $900 \mathrm{~J} \mathrm{~kg}^{-1} \mathrm{~K}^{-1}[21]$ \\
Thermal conductivity, $k$ & $1 \mathrm{~W} \mathrm{~m}^{-1} \mathrm{~K}^{-1}[20]$ \\
Fracture energy, $R$ & $10 \mathrm{~J} \mathrm{~m}^{-2}$ \\
\hline
\end{tabular}




\section{Figure captions}

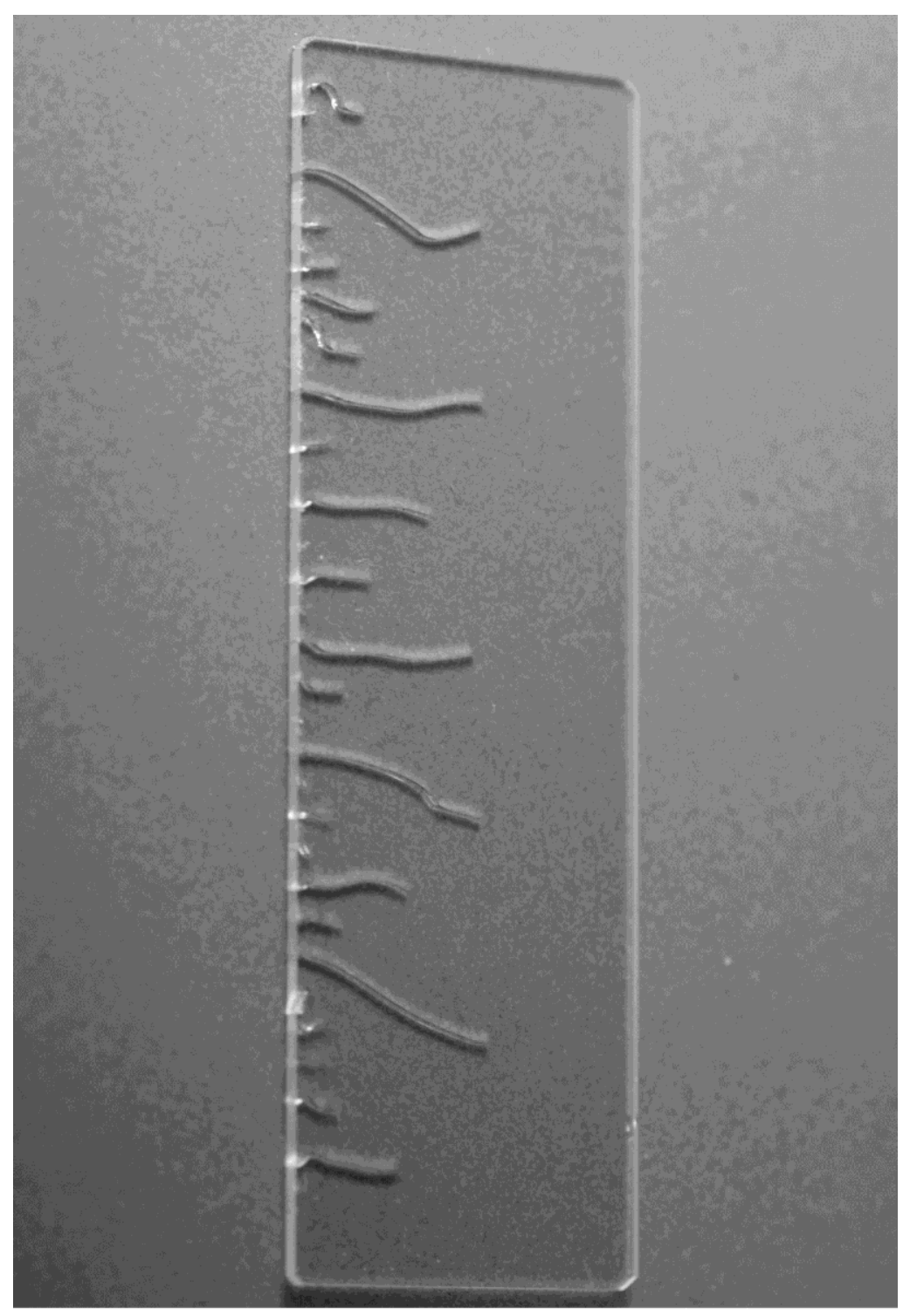

\section{$25 \mathrm{~mm}$}

Figure 1. Crack pattern obtained for a quench through $180 \mathrm{~K}$. Only the left edge of the sample was cooled and this results in through thickness cracks propagating from left to right. A large number of cracks was made to grow by scratching the cooled edge prior to the experiment but as cracks grow deeper their number is reduced through competition for the crack driving force. 


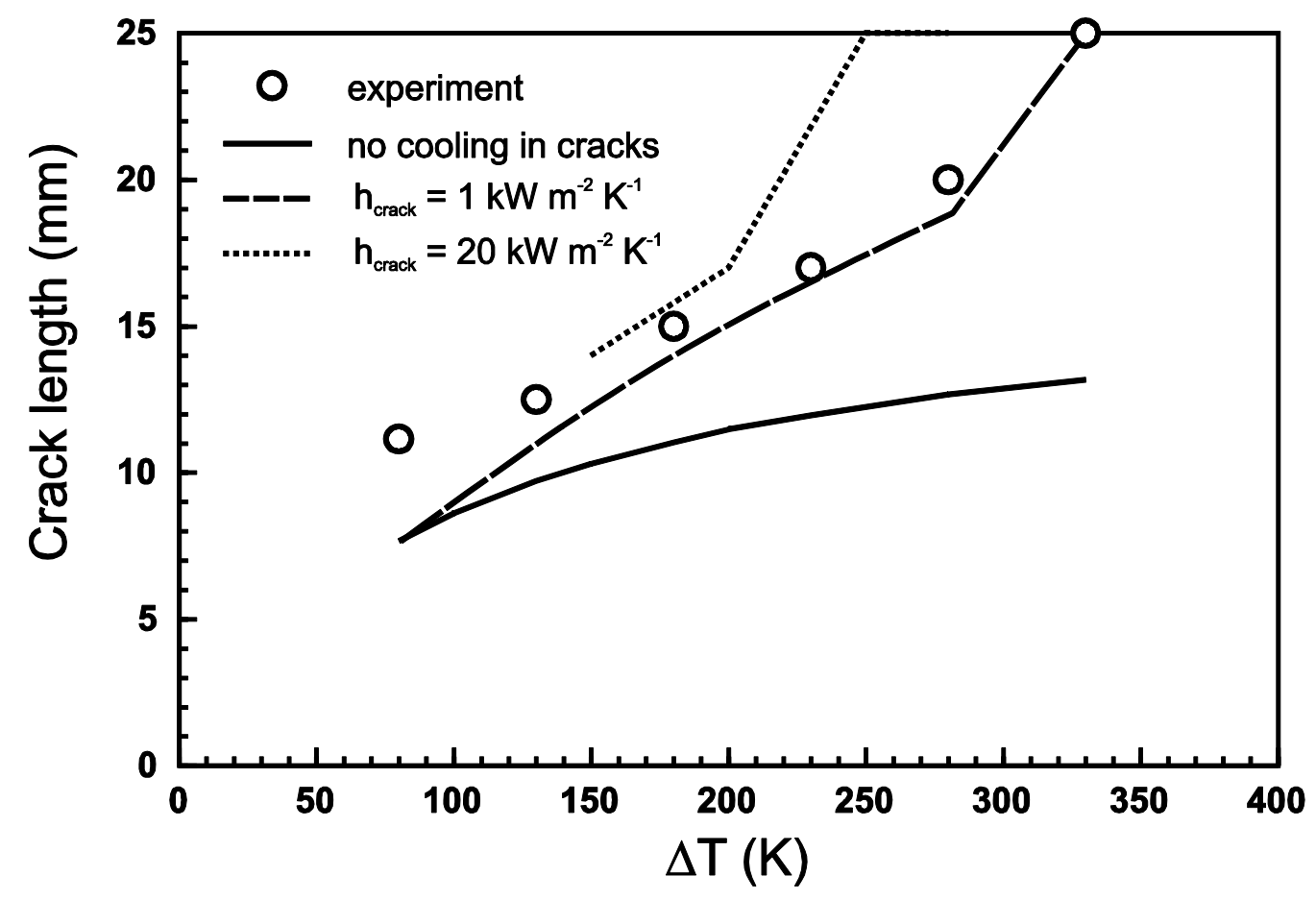

Figure 2. Experimentally determined crack lengths versus quench temperature difference, $\Delta T$, compared with predictions made assuming no cooling through the crack faces (solid line), assuming cooling through the crack faces is as efficient as through the front of the sample (dotted line) and assuming cooling through the crack faces is much less efficient than through the front (dashed line). Note that a crack length of $25 \mathrm{~mm}$ means that the crack has grown through the entire sample. 


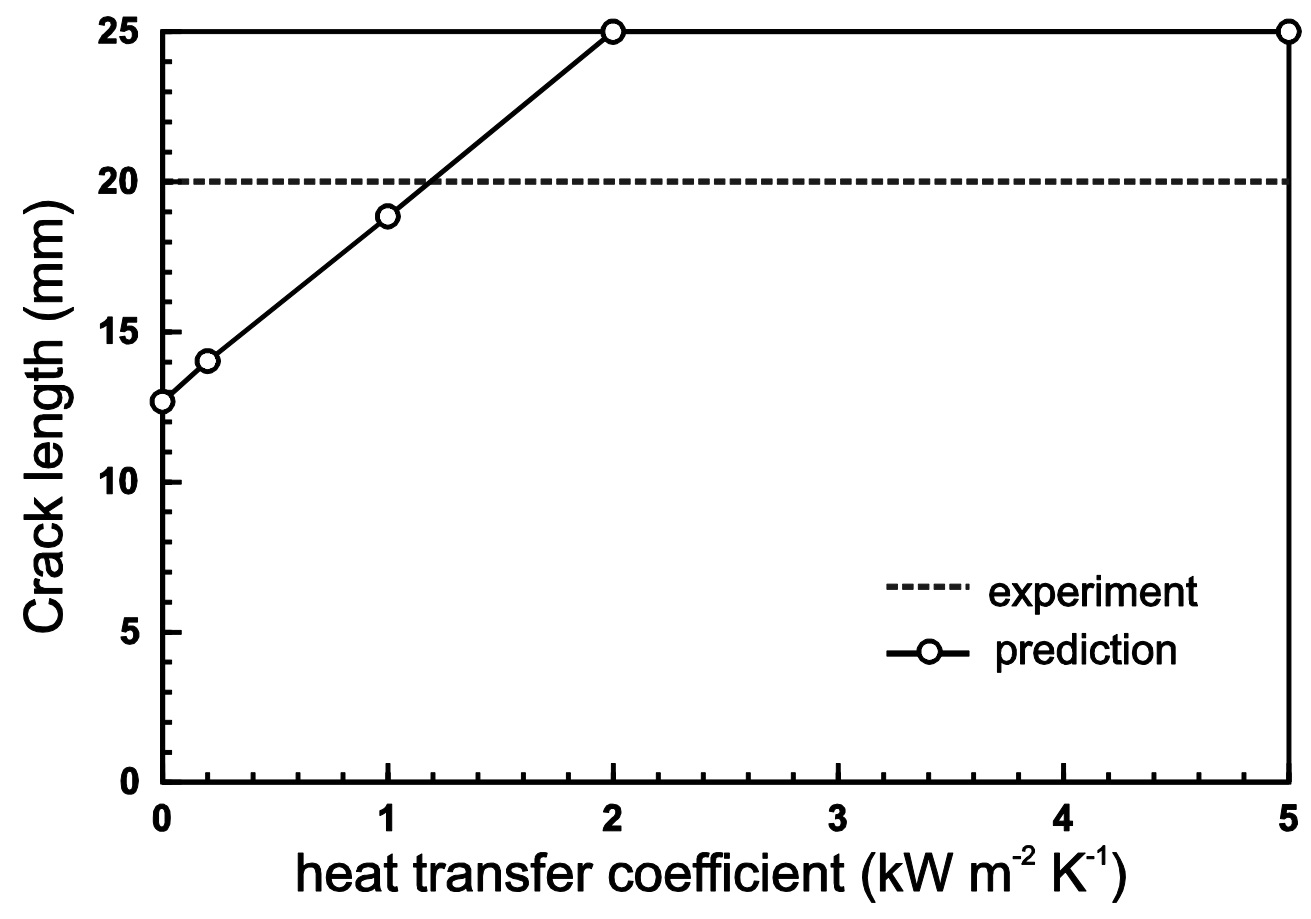

Figure 3. Prediction of the crack length for a quench through $300 \mathrm{~K}$ for different assumed values of the heat transfer coefficient, $h$, in the crack. For ease of comparison, the experimental crack length is show as a dashed line. 

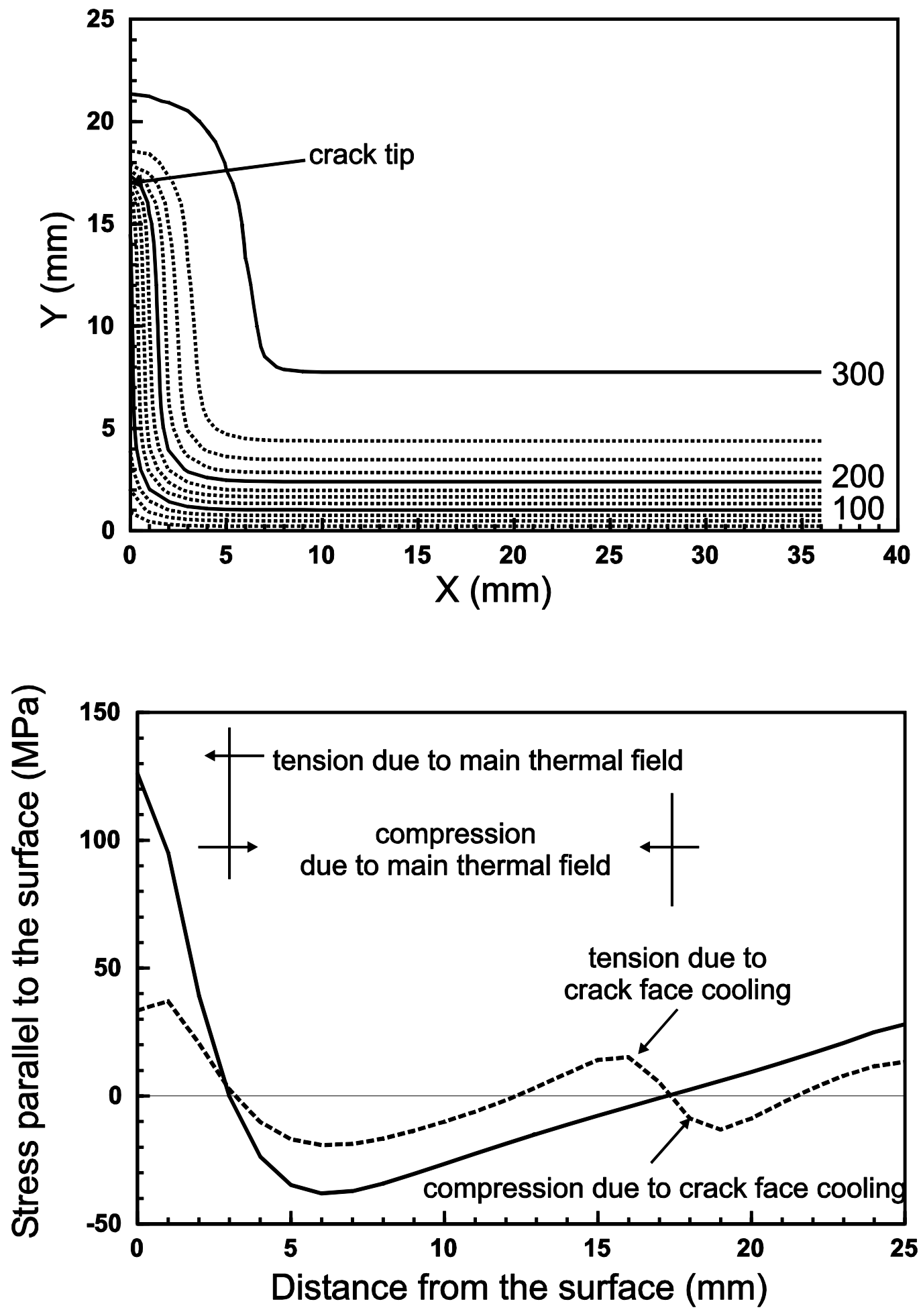

Figure 4. (a) calculated temperature distribution in half the sample with the centre of the sample on the left assuming cooling in the crack $\left(h=1 \mathrm{~kW} \mathrm{~K}^{-1} \mathrm{~m}^{-2}\right)$. The distribution shown is for $5 \mathrm{~s}$ after the glass slide was quenched through a $\Delta \mathrm{T}$ of $300 \mathrm{~K}$. The cooling in the crack causes a cold front to penetrate into the sample. In absence of crack face cooling such cold front does not form. (b) the stress distribution along the centre line for the case where there is no cooling in the crack (solid line) and for the case where the temperature distribution is altered by the presence of crack face cooling for the same time and conditions as in (a). 


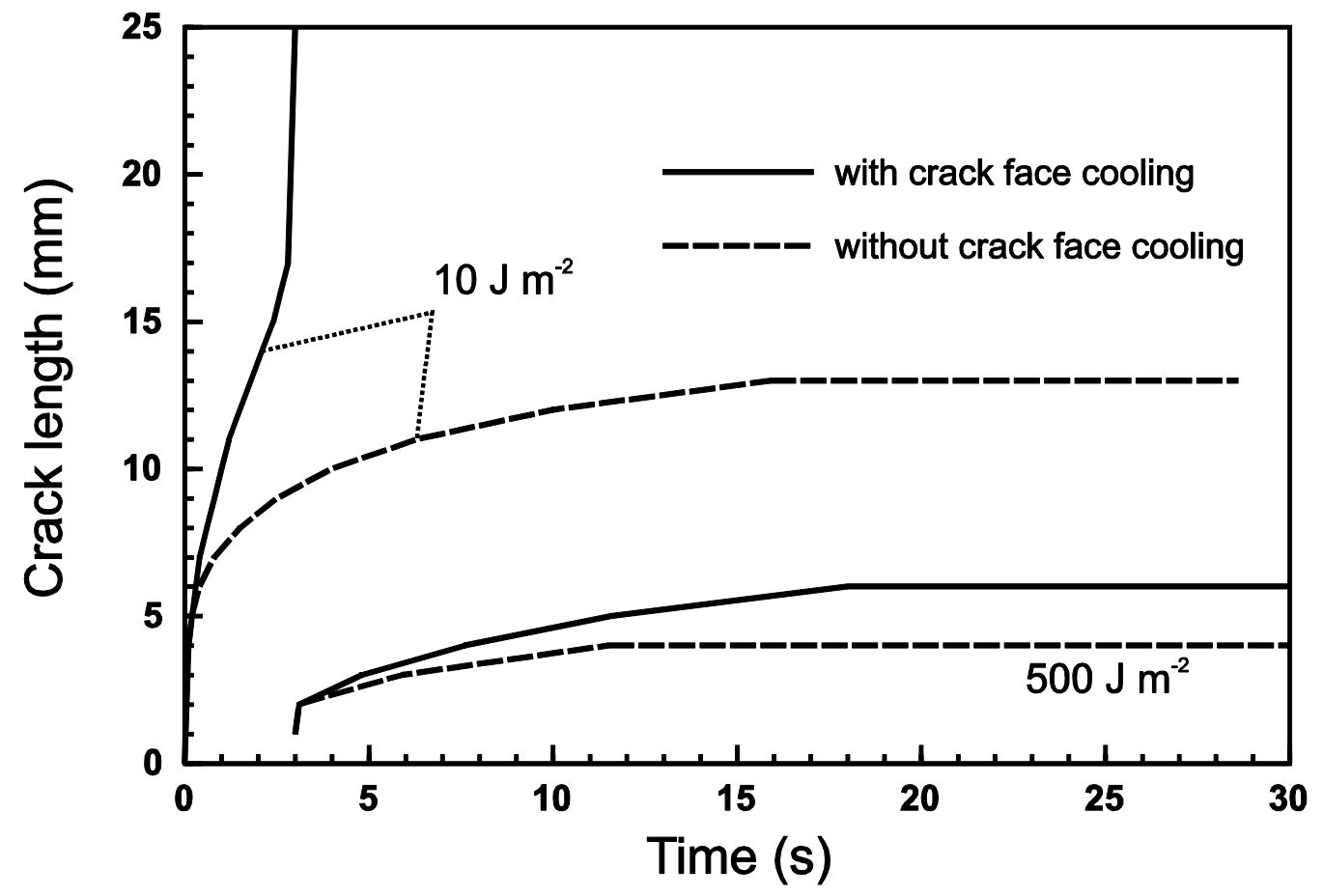

Figure 5. Simulated evolution of crack length versus time with our without crack face cooling assuming a fracture energy of $10 \mathrm{~J} \mathrm{~m}^{-2}$ or $500 \mathrm{~J} \mathrm{~m}^{-2}$ for a quench through $300 \mathrm{~K}$. The heat transfer coefficient in the crack was set to $1 \mathrm{~kW} \mathrm{~K}^{-1} \mathrm{~m}^{-2}$. 


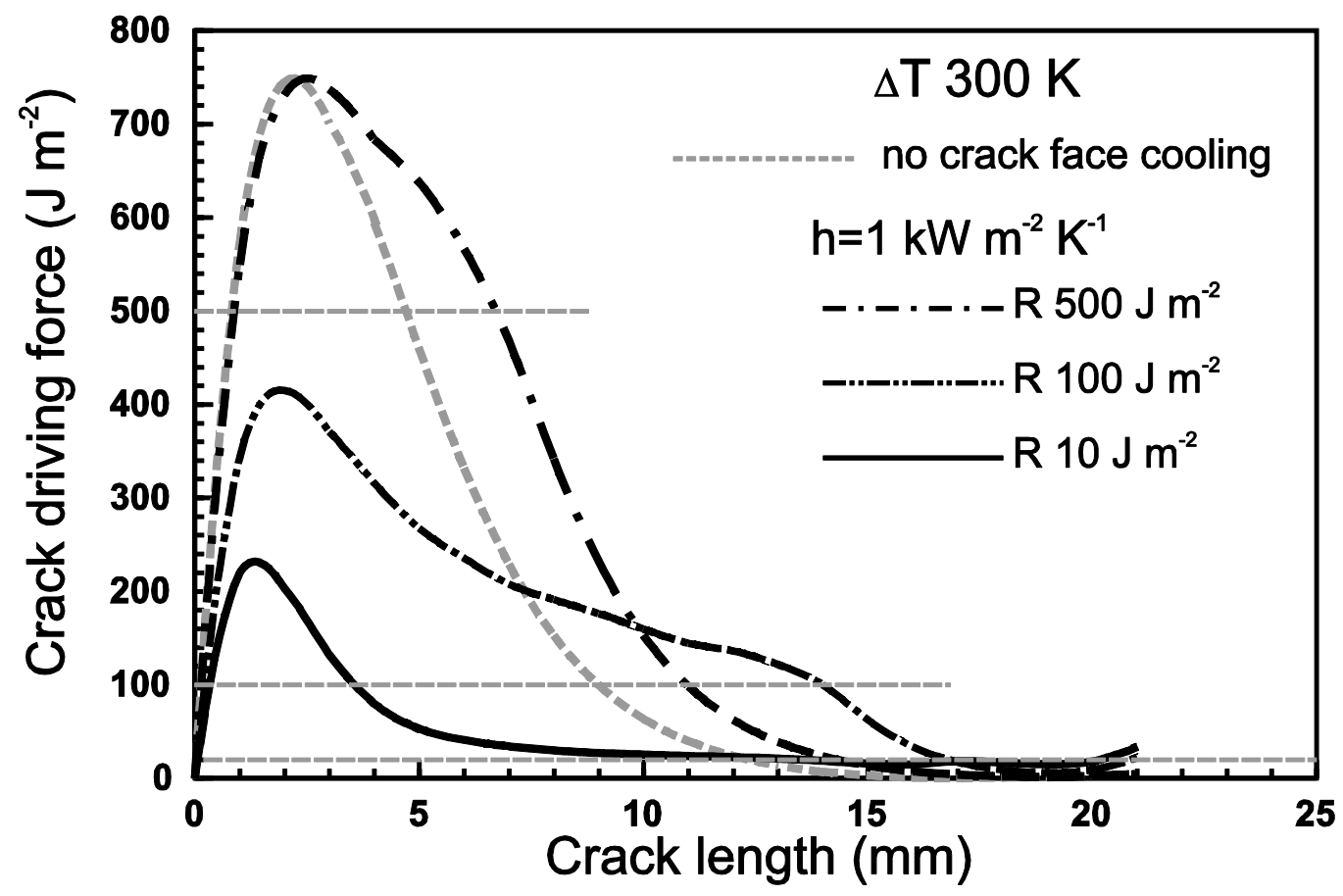

Figure 6. Prediction of the crack length assuming the heat transfer coefficient, $h$, in the crack amounts to $1 \mathrm{~kW} \mathrm{~K}^{-1} \mathrm{~m}^{-2}$ for $\Delta \mathrm{T}=300 \mathrm{~K}$ for 3 assumed fracture energies : 10,100 and $500 \mathrm{~J} \mathrm{~m}^{-2}$. For ease of comparison these fracture energies are indicated by horizontal lines, and the envelope curve of maximum $G$ values without cooling in the crack is also shown. 